\title{
Pyogenic granuloma of the colon
}

A 54-year-old man who had been suffering from abdominal pain for several months was admitted for minor rectal bleeding. Physical examination found mild abdominal tenderness in the left upper quadrant, and was otherwise unremarkable. The following laboratory indices were found: hemoglobin rate, $13.9 \mathrm{~g} / \mathrm{dL}$; white blood cell count, $14000 / \mathrm{mm}^{3}$; C-reactive protein, $12 \mathrm{mg} / \mathrm{dL}$. Colonoscopy revealed a pedunculated polyp of the descending colon with a short, wide stalk and a 20-mm large white-coated head with superficial ulceration ( Fig.1). The surrounding mucosa displayed a pseudopolypoid pattern, for which biopsies demonstrated non-specific inflammation. A clip was placed as a landmark before a 64-section computed tomography (CT) scan was undertaken. CT scan showed segmental colitis and hyperenhancement of the polyp ( Fig. 2). Snare polypectomy was performed. Pathological examination showed a proliferation of capillaries in a lobular arrangement that extended to the depth of the stalk ( $\bullet$ Fig.3 and $\bullet$ Fig.4). A diagnosis of pyogenic granuloma was upheld.

Pyogenic granuloma is a benign subtype of hemangioma, very common on the skin and on nasal and oral mucosal surfaces, but extremely rare in the gastrointestinal tract and especially in the colon [1-3]. When symptomatic, bleeding is the most common presentation. Pyogenic granuloma can be safely removed endoscopically. Its pathogenesis is still under discussion. Some authors postulate that pyogenic granuloma develops as a result
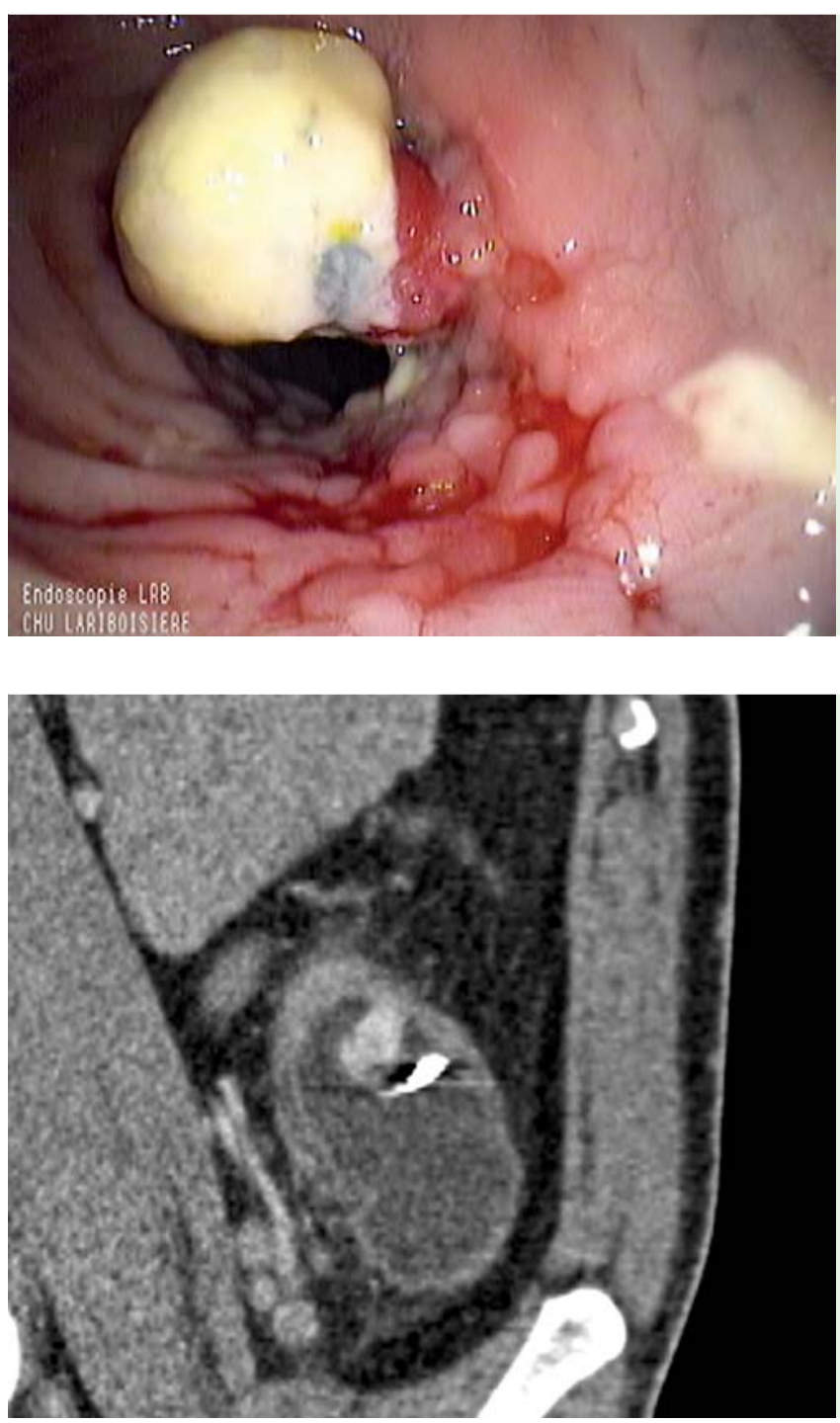

Fig. 1 Endoscopic view of the polyp in the descending colon.

Fig. 2 Computed tomography (CT)-scan view of the polyp in the descending colon, with segmental colitis and hyperenhancement of the polyp. A clip placed as a landmark during endoscopy is visible in the close vicinity of the polyp. of trauma or injury, while other authors believe that the associated stroma undergoes secondary inflammation and granulation tissue reaction [1].

Endoscopy_UCTN_Code_CCL_1AD_2AJ

\section{Competing interests: None}

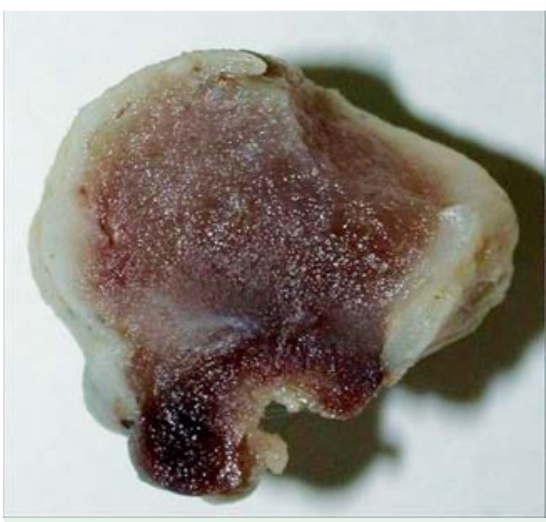

Fig. 3 Macroscopic pathological view of the polyp after endoscopic removal. 


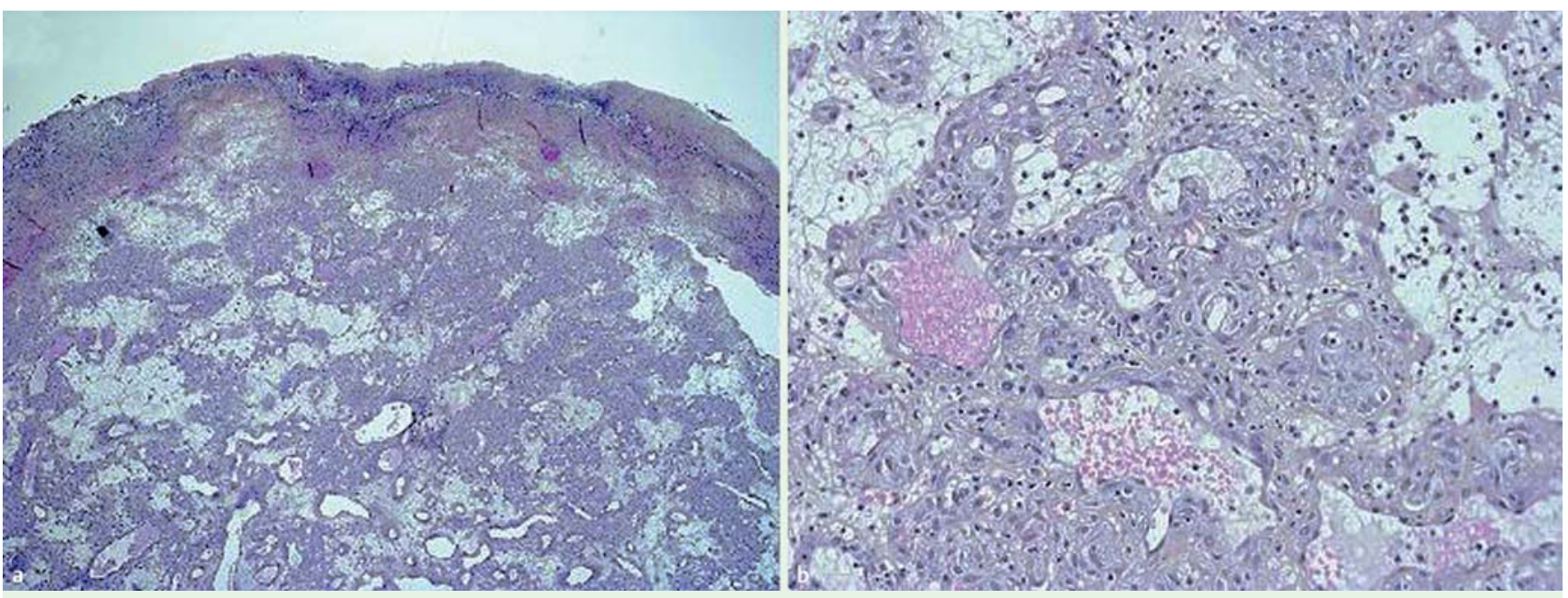

Fig. 4 Histological view of the polyp (hematein-eosin-saffron stain). Magnification: a original magnification $\times 25$; $\mathbf{b}$ original magnification $\times 250$.

\section{A. Thibault ${ }^{1}$, A. Lavergne-Slove' ${ }^{2}$, P. Soyer ${ }^{3}$, V. Ozenne ${ }^{1}$, P. Marteau ${ }^{1}$, X. Dray ${ }^{1}$}

${ }^{1}$ Department of Digestive Diseases, APHP, Lariboisière Hospital and Paris Diderot Paris 7 University, Paris, France

2 Department of Cytology and Pathology, APHP, Lariboisière Hospital and Paris Diderot Paris 7 University, Paris, France

${ }^{3}$ Department of Abdominal Imaging, APHP, Lariboisière Hospital and Paris Diderot Paris 7 University, Paris, France

\section{References}

1 González-Vela CM, Val-Bernal FJ, Garijo FM et al. Pyogenic granuloma of the sigmoid colon. Ann Diagn Pathol 2005; 9: 106 - 109

2 Yao T, Nagai E, Utsunomiya $T$ et al. An intestinal counterpart of pyogenic granuloma of the skin. A newly proposed entity. Am J Surg Pathol 1995; 19: 1054-1060

3 Moparty B, Xiao S, Bhutani MS. Pyogenic granuloma presenting as a rectal polyp at the site of a previous polypectomy. Endoscopy 2006; 38: E2-E3

\section{Bibliography}

DOI http://dx.doi.org/

10.1055/s-0031-1291697

Endoscopy 2012; 44: E155-E156

(c) Georg Thieme Verlag KG

Stuttgart · New York

ISSN 0013-726X

\section{Corresponding author}

\section{Dray, MD, PhD}

Department of Digestive Diseases

Lariboisière Hospital APHP and Paris Diderot

Paris 7 University

2 rue Ambroise Paré

75010 Paris

France

Fax: +33-1-49952577

xavier.dray@lrb.aphp.fr 